\title{
Bedtime Parenting Practices Associated with Social-emotional Competence in Thai Infants
}

\author{
Nattaporn Tassanakijpanich, M.D. ${ }^{1}$, Stephen Durako, BA. ${ }^{2,3}$, Utcharee Intusoma, M.D., Ph.D. ${ }^{4}$ \\ 'Division of Child Development, Department of Pediatrics, Faculty of Medicine, Prince of Songkla University, Hat Yai, \\ Songkhla 90110, Thailand. \\ 2Durako Consulting, LLC, Seattle, Washington State, The United States of America. \\ ${ }^{3}$ Faculty of Medicine, Prince of Songkla University, Hat Yai, Songkhla 90110, Thailand. \\ ${ }^{4}$ Division of Neurology, Department of Pediatrics, Faculty of Medicine, Prince of Songkla University, Hat Yai, Songkhla 90110, \\ Thailand.
}

Received 23 June 2020 • Revised 8 September 2020 • Accepted 18 September 2020 • Published online 5 February 2021

\begin{abstract}
:
Objective: We aimed to determine the association between bedtime parenting practices and infant social-emotional competence (SEC).

Material and Methods: Data from a birth cohort called: Prospective Cohort Study of Thai Children, were analyzed. Information on bedtime parenting and infant's sleep information were collected at 3 and 12 months of age. Modified Infant-Toddler Social and Emotional Assessment (MITSEA) were used to measure the SEC at 12 months of age. All participating infants with a MITSEA score $>75^{\text {th }}$ percentile were classified as having high SEC. The association between bedtime parenting practices and high SEC were analyzed using multiple logistic regression.

Results: Data from 2,109 infants were analyzed (male:female=1:1). Median age of mothers was 26 years. Ninety-two percent of caregivers shared a bed with their infants, at either their $3^{\text {rd }}-$ or $12^{\text {th }}$-month-visits. Two-thirds of the caregivers reported bed sharing at both visits. About $70.0 \%$ of caregivers fed their infants until the infant fell asleep, and about two-thirds responded to infant's awakening with milk feeding. Infants who were never fed until falling asleep were more likely to have high SEC, compared with infants who were always fed until sleep (odds ratio 1.49; 95\% confidence interval 1.14, 1.96). Bed sharing showed no association with a high SEC. Older, female mothers, higher socioeconomic status and quality time were associated with a high SEC.
\end{abstract}

Contact: Utcharee Intusoma, M.D., Ph.D.

Division of Neurology, Department of Pediatrics, Faculty of Medicine, Prince of Songkla University, Hat Yai, Songkhla 90110, Thailand.

E-mail: utchareei@yahoo.com

(c) 2021 JHSMR. Hosting by Prince of Songkla University. All rights reserved.

This is an open access article under the CC BY-NC-ND license

(http://www.jhsmr.org/index.php/jhsmr/about/editorialPolicies\#openAccessPolicy).
J Health Sci Med Res 2021;39(4):283-292 doi: 10.31584/jhsmr.2021784 www.jhsmr.org 
Conclusion: The bedtime parenting practice associated with a high SEC was: "non-feeding until falling asleep". Bed sharing, which was a popular practice in this cohort, showed no association with high SEC.

Keywords: bedtime, infant, parenting, sleep, social-emotional competence

\section{Introduction}

Social-emotional competence (SEC) is an ability comprising of self-regulation, social awareness, social problem solving and prosocial behaviors. ${ }^{1}$ While small children learn their social-emotional skills through a mutual interaction with caregivers and peers, infants develop their SEC through an interaction between neuromaturation and reciprocity with their caregiver. ${ }^{2}$ Studies show that SEC has gained more attention, because it is related to healthy lifestyles, success, happiness and quality of life. ${ }^{1-3}$

Sleep patterns can reflect the maturation in a child's self-regulation. ${ }^{2,3}$ Sleep consolidation begins in the early infancy period. Typical infants are able to self-sooth, and regulate their sleep at ages between 6 weeks to 3 months old. ${ }^{2-4}$ Sleep problems impact not only the child development and behaviors ${ }^{4-9}$, but also disturb maternal sleep and increase maternal distress. ${ }^{10,11}$ Norwegian and Australian cohorts found an association between low sleep quality at preschool age and poorer socio-emotional health at school age. ${ }^{7,8}$ The social-emotional issues are not observed if the sleep problem resolves before 4 years of age, suggesting potential benefit of early intervention. ${ }^{8}$

Bedtime parenting and child rearing styles vary among cultures. ${ }^{12-15}$ Common bedtime routines in Western countries include feeding, bathing, reading bedtime story and letting children sleep by themselves. ${ }^{12,15}$ Bed-sharing is not recommended in Western countries, as it is associated with an increased risk of sudden infant death syndrome as well as behavioral problems. ${ }^{14,15}$ In Thailand; however, parents sharing a bed with their infant is very common. ${ }^{13,16}$
An infant's sleep pattern develops through parentinfant interconnection ${ }^{2,17,18}$; however, which parenting style should be recommended is debatable. On one hand, limiting parental involvement in sleep training (i.e. gradual extinction and bedtime fading) may promote infant's selfregulation. ${ }^{4,18,19}$ On the other hand, encouraging prompt response to the infant's cues at bedtime may help reduce infant and parental distress. ${ }^{20-22}$

There has been limited evidence concerning the link between bedtime parenting and childrens SEC. Culturalspecific bedtime practices may result in different impacts on a child's SEC. Hence, we aimed to determine whether bedtime parenting in the infancy period was associated with SEC. Finding bedtime practices that promote SEC may change recommendations regarding bedtime parenting in countries with similar contexts.

\section{Material and Methods}

\section{Participants}

The present study analyzed data from a Thai birth cohort called: Prospective Cohort Study of Thai Children (PCTC). The PCTC was an observational, communitybased study designed to follow all fetuses from the 28 to 38 weeks gestational age, from four selected districts (namely: Panomtuan District in Kanchanaburi, Thepa District in Songkla, Kranuan District in Khon Kaen and Muang District in Nan) in different regions of Thailand and the Bangkok metropolitan area. The 5 study sites were chosen considering socio-economic factors and feasibility of longterm follow-up. All children born between October, 2000 
and November, 2002, in the selected sites, were recruited and followed-up. Data from home-visits at age 21 days, 28 days, 3 months, 6 months, and 12 months were gathered by trained field research assistants. After standardization among study sites, all research assistants followed the interviewing instructions, and used specific questionnaires for each home visit.

\section{Measures}

\section{Social-emotional competence}

Social-emotional competence was measured using the Modified Infant-Toddler Social and Emotional Assessment (MITSEA) at the 12-month-visit. MITSEA for 12-month-old children comprised of 26 items and 6 components (i.e. compliance, attention, imitation/play, mastery motivation, empathy and prosocial peer relations). Cronbach's alpha of MITSEA, Thai version was $0.89 .^{23}$ The caregiver was asked to take one MITSEA card at a time. Each card contained a statement indicating a child's behavior, e.g., "imitate pat-a-cake or wave bye-bye". Then the parent placed each card into one of 4 boxes, which were labeled as follows: Very True/Often, Somewhat True/Sometimes, Not True/Rarely and No Opportunity. These were scored 2, 1, 0, and NA, respectively. Having a MITSEA score $>75^{\text {th }}$ percentile of the study population was classified as having "High SEC".

\section{Bedtime parenting}

At 3-month and 12-month-visits, the main caregiver was asked about his/her bedtime parenting within two weeks prior to the interview. Questions included bed sharing, main bedtime activities used to introduce infant's sleep (e.g. "feeding until the infant fell asleep", "holding until the infant fell asleep"), and activities used to respond to night awakening of the infant. In the analysis, each bedtime practice was then classified into 4 groups, these being: "never”, "at 3-month-visit only", "at 12-month-visit only" and "at both visits".

\section{Covariates}

Potential confounders collected were demographic data, infant's sleep information and child rearing. Data on day care attendance, breastfeeding, and the bedtime caregiver were gathered at both 3 and 12-monthvisits. Infant's sleep information included number of night awakenings and naps per day. Maternal contingent responsiveness was measured at the 3-month-visit, by observing mutual interactions between mother and infant during feeding time. The mutual interactions of interest consisted of gentle holding, soft touching, eye contact, smiling, reciprocal conversation and relaxing interaction. A trained observer gave a score from 1-4 for each interaction, using a rubric score with a clear description. A total score $>75^{\text {th }}$ percentile of the study population was classified as: "High contingent response". Data on "Quality time” was collected at the 3-month visit, by asking about quality activities. Regularity of strolling, playing with toys and singing with infants were labeled, and scored as: never (0 point), some days (1 point) or every day (2 points). A Total score higher than the $75^{\text {th }}$ percentile of the study population was considered as "High quality time".

The PCTC study was approved by the Ethical Committee, Ministry of Public Health. All families were informed about the study procedures and potential risks before giving written consent. This present, retrospective study was further approved by the Ethics Committee of the Faculty of Medicine, Prince of Songkla University, Songkhla, Thailand (COA 60-333-01-1). This analysis did not receive any grant from funding agencies in the public, commercial or not-for-profit sectors. 


\section{Statistical analysis}

Univariate analysis was performed and independent variables, which related to the dependent variable ( $p$-value from chi-square statistics <0.20) or were potential confounders, were selected. Stepwise multiple logistic regression was applied to determine an association between bedtime practices and high SEC. Multicollinearity and interaction terms between bedtime practice and each covariate were checked prior to the model fitting. The final model contained all interesting variables, with minimum Akaike information criterion value. Only records with complete data of the relevant variables were used in the analysis. Robustness of the study was subsequently checked by comparing baseline characteristics of analyzed children and children excluded due to missing data. The results were presented as adjusted odds ratio (aOR), with a $95 \%$ confidence interval. The level of significance between the high SEC group and low SEC group was a defined p-value from Wald test and LR test $<0.05$. All analyses were applied by using $\mathrm{R}$ program version 3.5.3. ${ }^{24}$

\section{Results}

Figure 1 shows a flow of the number of participants excluded before final analysis. There were 4,245 live births during the enrollment period. Infants with prematurity, low birth weight, significant perinatal problems and twins were excluded. After we excluded the records with missing data of interest, there were 2,109 records with complete data at the 12-month-visit.

\section{Baseline characteristics of participants}

Male and female ratio was equal. Most infants were raised by mothers (Table 1). About half of the parents had a secondary school level education, and less than $10.0 \%$ had completed any higher education. About one third of fathers were unemployed, and one third of caregivers reported a negative financial balance.

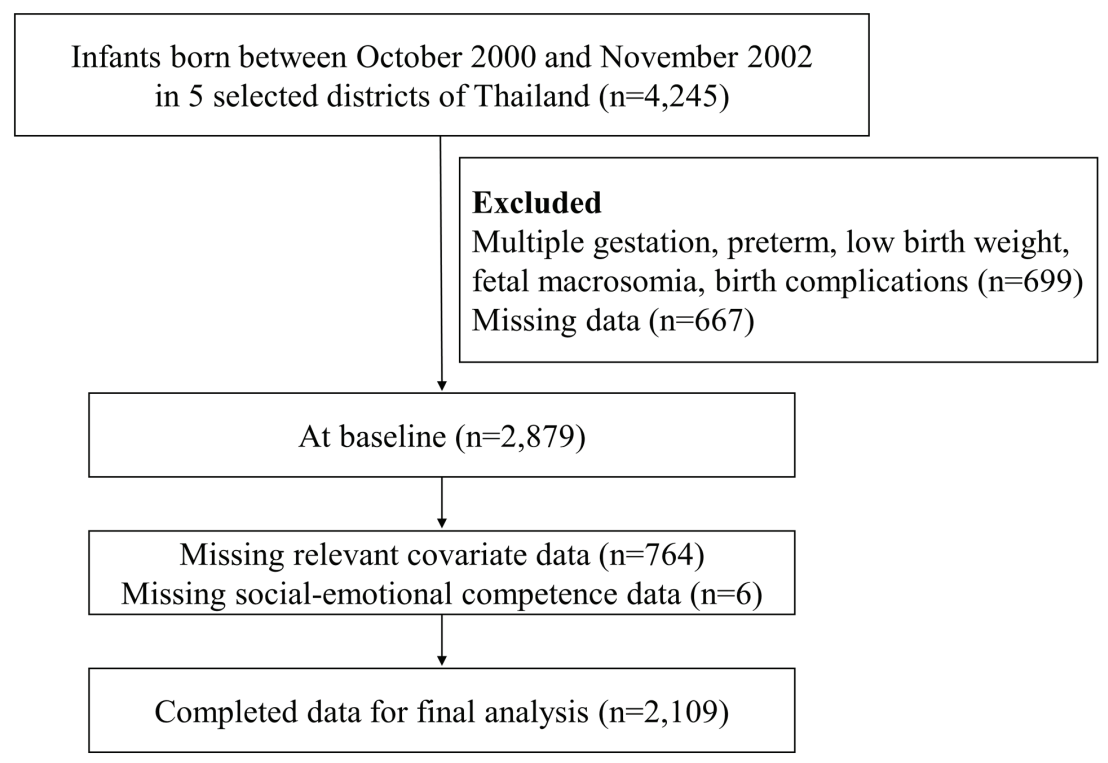

Figure 1 Flow of study participants 
Table 1 Baseline characteristics of participants $(n=2,879)$

\begin{tabular}{ll}
\hline Characteristics & Number (\%) \\
\hline Males & $1,420(49.3)$ \\
First child & $1,266(44.3)$ \\
Paternal age (years), median (IQR) & $30(25.0,35.0)$ \\
Maternal age (years), median (IQR) & $26(22.0,31.0)$ \\
Father's education & \\
$\quad$ Primary school & $1,194(47.3)$ \\
Secondary school and vocational school & $1,044(41.3)$ \\
Bachelor's degree and higher & $221(8.7)$ \\
Mother's education & \\
Primary school & $1,380(48.3)$ \\
Secondary school and vocational school & $1,087(38.0)$ \\
Bachelor's degree and higher & $280(9.8)$ \\
Father's occupation & \\
Unemployed & $886(34.9)$ \\
Own business & $220(8.7)$ \\
Company employee and government officer & $1,428(56.3)$ \\
Mother's occupation & \\
Unemployed & $651(22.7)$ \\
Own business & $1,221(42.6)$ \\
Company employee and government officer & $731(25.5)$ \\
Mother as a bedtime caregiver at age 3 months & $2,434(85.6)$ \\
Mother as a bedtime caregiver at age 12 months & $2,270(80.7)$ \\
Number of family members & \\
2-3 & $430(15.3)$ \\
4-5 & $1,302(46.3)$ \\
>5 & $1,079(38.4)$ \\
Monthly family income (THB), median (IQR) & $8,333(4,312.5$, \\
Adequate income, $n$ (\%) & $16,166.7)$ \\
Regularly live together & $1,802(62.9)$ \\
Attending day care at age 3 months & $2,552(89.3)$ \\
Attending day care at age 12 months & $281(9.9)$ \\
Breastfeeding at age 3 months & $594(21.1)$ \\
Breastfeeding at age 12 months & $2,183(77.4)$ \\
Infant's temperament & $1,469(53.3)$ \\
Easy temperament & \\
Slow to warm-up temperament & $1,268(45.0)$ \\
Difficult temperament & $442(15.7)$ \\
Mixed type temperament & $184(6.5)$ \\
\hline & $921(32.7)$ \\
\hline
\end{tabular}

$\mathrm{IQR}=$ interquartile range, $\mathrm{THB}=$ Thai Baht

\section{Infant's sleep characteristics}

Most infants had night awakenings before 12 months of age (Table 2). Approximately, $75.0 \%$ of them had persistent night awakening at both visits. Over $40.0 \%$ took a nap more frequently than a typical 3-month-old infant. We checked and found a significant correlation between night awakening and frequency of naps: more frequent napping was associated with night awakening. To reduce the co-linearity effect, only the night awakening variable was used as a covariate in our multivariate analysis.

Table 2 Infant's sleep characteristics and bedtime parenting $(n=2,879)$

\begin{tabular}{ll}
\hline Infant's sleep characteristics & Number (\%) \\
\hline Night awakening ( $\mathrm{n}=2,463)$ & $16(0.6)$ \\
Never & $608(24.7)$ \\
At 3 month-visit only & $39(1.6)$ \\
At 12 month-visit only & $1,800(73.1)$ \\
At both visits & \\
Naps at 3 months ( $\mathrm{n}=2,511)$ & $1,404(55.9)$ \\
$2-3$ times/day & $998(39.7)$ \\
$4-5$ times/day & $94(3.7)$ \\
$\geq 6$ times/day & \\
Bedtime parenting & \\
Bed-sharing ( $\mathrm{n}=2,783)$ & $212(7.6)$ \\
Never & $118(4.2)$ \\
At 3 month-visit only & $664(23.9)$ \\
At 12 month-visit only & $1,789(64.3)$ \\
At both visits & \\
Feeding until infant fell asleep ( $\mathrm{n}=2,782)$ & $812(29.2)$ \\
Never & $556(20.0)$ \\
At 3 month-visit only & $475(17.1)$ \\
At 12 months-visit only & $939(33.8)$ \\
At both visits & \\
Feeding as a response to infant's awakening & \\
(n=2,465) & $97(3.9)$ \\
Never & $555(22.5)$ \\
At 3 month-visit only & $174(7.1)$ \\
At 12 month-visit only & $1,639(66.5)$ \\
At both visits & \\
\hline
\end{tabular}

\section{Bedtime parenting Bed sharing}

At 3 months old, almost $70.0 \%$ of parents shared a bed with their infants, and about 30.0\% slept in a separate bed from their infants; but in the same room (Table 2). Percentage of bed sharing increased to $88.0 \%$ at the 12 -month-visit. Less than $10.0 \%$ of parents never shared a bed with their infant. The median frequency of night awakening in infants, who shared a bed with the caregiver, was 3 [interquartile range (IQR) 2, 3] per night, 
which was not different from the infants who did not share a bed.

\section{Feeding until infant fell asleep}

About half of the parents fed their infant until the infant fell asleep, at both 3-month and 12-month-visits. About $30.0 \%$ denied this practice at both visits.

\section{Feeding as a response to infant's awakening}

When 3-month-old infants woke up during the night, almost $90.0 \%$ of parents helped sooth the infant back to sleep by feeding the infant. Two-thirds of parents practiced this at both visits.

\section{Social-emotional competence}

MITSEA was assessed in 2,818 infants at 12 months of age. Median SEC score was 0.97 (IQR 0.78, 1.18). Females had higher SEC scores than males [odds ratio (OR) 1.26; 95\% Cl 1.01, 1.55] i.e. females median SEC was 0.97 (IQR 0.79, 1.20), and the male median SEC was 0.95
(IQR 0.77, 1.15). This statistically significant difference is primarily a function of a large sample size; the magnitude of the difference is small and not likely to be clinically important. Seven hundred and eleven infants were classified as being in the "high SEC" group, as their SEC score was more than the $75^{\text {th }}$ percentile of study population.

\section{Association between bedtime parenting and high} SEC

Multiple logistic regression (Table 3 ) found that female, first born infant, older maternal age, higher parental education and high-quality time were associated with high SEC.

Regarding the bedtime parenting, infants never fed until the infant fell asleep had about a 1.5 greater chance to have high SEC compared with infants always fed until falling asleep (OR 1.49; 95\% Cl 1.14, 1.96). Bed-sharing and night awakening feeding showed no significant association with high SEC.

Table 3 Multiple logistic regression predicting high social-emotional competence $(n=2,109)$

\begin{tabular}{|c|c|c|c|c|}
\hline Variables & $\begin{array}{l}\text { High SEC } \\
\text { Number (\%) }\end{array}$ & $\begin{array}{l}\text { Low SEC } \\
\text { Number }(\%)\end{array}$ & aOR $(95 \% \mathrm{Cl})$ & $\mathrm{Pa}$ \\
\hline Female (ref: male) & $391(55.0)$ & $1,041(49.4)$ & $1.26(1.01,1.55)^{*}$ & $<0.05$ \\
\hline Maternal age (ref: <20 years) & & & & $<0.05$ \\
\hline 20-29 years & $387(55.0)$ & $1,190(56.7)$ & $2.19(1.41,3.40)^{\star \star \star}$ & \\
\hline 30-39 years & 241 (34.3) & $595(28.4)$ & $2.38(1.44,3.94)^{\star \star \star}$ & \\
\hline$\geq 40$ years & $26(3.7)$ & $46(2.2)$ & $2.38(1.03,5.48)^{\star}$ & \\
\hline Paternal age (ref: <20 years) & & & & NS \\
\hline 20-29 years & $244(39.9)$ & 907 (48.4) & $0.77(0.37,1.58)$ & \\
\hline 30-39 years & 277 (45.3) & $729(38.9)$ & $1.07(0.50,2.27)$ & \\
\hline$\geq 40$ years & $76(12.4)$ & $186(9.9)$ & $1.19(0.52,2.71)$ & \\
\hline Mother's edu $\geq 2^{\circ}$ school (ref: $<2^{\circ}$ ) & 437 (62.2) & $902(43.0)$ & $1.48(1.15,1.92)^{\star \star \star}$ & $<0.05$ \\
\hline Father's edu $\geq 2^{\circ}$ school $\left(\right.$ ref: $<2^{\circ}$ ) & $400(65.4)$ & $841(45.1)$ & $1.47(1.14,1.90)^{\star \star \star}$ & $<0.05$ \\
\hline Maternal occupation (ref: unemployed) & & & & $<0.05$ \\
\hline Officer & $190(27.0)$ & $527(25.1)$ & $1.41(0.96,2.09)$ & \\
\hline Own business & $370(52.5)$ & $812(38.7)$ & $1.88(1.33,2.66)^{\star \star \star}$ & \\
\hline Paternal occupation (ref: unemployed) & & & & NS \\
\hline Officer & $371(60.6)$ & $1,020(54.4)$ & $1.08(0.82,1.42)$ & \\
\hline Own business & 75 (12.3) & $139(7.4)$ & $1.06(0.67,1.67)$ & \\
\hline
\end{tabular}


Table 3 (continued)

\begin{tabular}{|c|c|c|c|c|}
\hline Variables & $\begin{array}{l}\text { High SEC } \\
\text { Number (\%) }\end{array}$ & $\begin{array}{l}\text { Low SEC } \\
\text { Number (\%) }\end{array}$ & aOR $(95 \% \mathrm{Cl})$ & $\mathrm{Pa}$ \\
\hline First born (ref: no) & $345(49.2)$ & $891(42.6)$ & $1.35(1.05,1.73)^{\star}$ & $<0.05$ \\
\hline Breastfed at 1 year (ref:bottle fed) & $509(74.4)$ & $1,680(81.1)$ & $1.10(0.82,1.46)$ & NS \\
\hline High contingent responses (ref: no) & $157(27.4)$ & $360(19.9)$ & $1.21(0.94,1.55)$ & NS \\
\hline High quality time (ref: no) & $293(50.3)$ & $564(29.9)$ & $1.74(1.39,2.16)^{\star \star \star}$ & $<0.05$ \\
\hline Night awakening (ref: at both ages) & & & & NS \\
\hline Never & $7(1.2)$ & $8(0.4)$ & $1.61(0.43,6.05)$ & \\
\hline At 3 months only & $149(25.7)$ & $458(24.5)$ & $1.23(0.91,1.66)$ & \\
\hline At 12 months only & $15(2.6)$ & $24(1.3)$ & $1.20(0.52,2.75)$ & \\
\hline \multicolumn{5}{|l|}{ Bedtime parenting } \\
\hline Bed-sharing (ref: never) & & & & NS \\
\hline At 3 months only & $19(2.7)$ & $99(4.8)$ & $0.48(0.23,1.02)$ & \\
\hline At 12 months only & $145(20.9)$ & $514(24.8)$ & $0.95(0.60,1.50)$ & \\
\hline At both ages & $484(69.8)$ & $1,294(62.4)$ & $0.95(0.62,1.46)$ & \\
\hline Feed until infant fell asleep (ref: at both ages) & & & & $<0.05$ \\
\hline Never & $257(37.1)$ & $550(26.5)$ & $1.49(1.14,1.96)^{*}$ & \\
\hline At 3 months only & $143(20.6)$ & $408(19.7)$ & $1.05(0.77,1.43)$ & \\
\hline At 12 months only & $97(14.0)$ & $374(18.1)$ & $0.94(0.68,1.30)$ & \\
\hline Feed to respond to infant's arousal (ref: never) & & & & NS \\
\hline At 3 months only & $126(21.7)$ & $426(22.7)$ & $1.10(0.59,2.03)$ & \\
\hline At 12 months only & $52(9.0)$ & $121(6.5)$ & $1.40(0.70,2.82)$ & \\
\hline At both visits & $373(64.3)$ & $1,261(67.3)$ & $1.18(0.64,2.18)$ & \\
\hline
\end{tabular}

$\mathrm{Pa}=\mathrm{P}$ from $\mathrm{LR}$ test, aOR=adjusted odds ratio, $\mathrm{Cl}=$ confidence interval, NS=non-significant, $\mathrm{SEC}=$ social-emotional competence, ref=reference $P$ from Wald test $\left({ }^{*} \mathrm{p}\right.$-value $<0.050,{ }^{* *} \mathrm{p}-$ value $<0.010,{ }^{* *} \mathrm{p}$-value $\left.<0.001\right)$

\section{Discussion}

We found an association between social-emotional competence and a specific bedtime parenting practice. At 1 year of age, infants who had never been fed until falling asleep had higher SEC than infants always receiving bedtime feeding until sleep. High SEC was also associated with female, older aged mothers, high socioeconomic status and high quality-time. Bed sharing, which was the most common bedtime parenting practice in this study, did not show an association with high SEC.

Inducing sleep by feeding the infant, until the infant fall asleep, may be unfavorable for child social-emotional development. Our results showed that infants who were always fed until sleep had lower SEC than those who had never, or were partly been fed until falling asleep. Rather than responding to an infant's cue, some caregivers fed their infant whether or not he or she was hungry. We hypothesize that feeding to introduce sleep suggested either a permissive or an authoritarian parenting style. Previous studies showed that either a permissive parenting style (high affection and low behavioral control) or an authoritarian parenting style might be related to poor emotional regulation strategies in children. ${ }^{25,26}$ Feeding infants when they do not feel hungry might disrupt an infant's self-regulation, which is the crucial factor in social-emotional development. ${ }^{27}$ 
Social emotional competence of children depends on both the individual's factors (e.g. temperament, resilience and cognitive ability) and external factors (e.g. stress, childrearing and culture).$^{1,3}$ Our findings support previous studies, showing that higher socioeconomic status is related to better child developmental outcomes and SEC., ${ }^{1,28}$ Being a mature (older) mother and spending high-quality time with infants are also linked to having high SEC.

Bed sharing is not recommended in Western countries, because it may increase parental involvement ${ }^{15,27}$ and infant's night awakening. ${ }^{15,29}$ Previous studies reported that bed sharing is related to a child's emotional problems. ${ }^{14,30}$ However, bed sharing was the most common bedtime parenting practice in our study, partly due to the popularity of breastfeeding in this cohort. More than half of our cohort mothers continued their breastfeeding for least 12 months. Many Thai parents share a bed with small infants; due to the convenience of nursing, and they feel more reassured about the safety of their infants. ${ }^{31}$ Although, bed sharing is not endorsed by recommendations in Western countries, this practice is widely held in developing countries, including Thailand. ${ }^{14}$ In our study, the frequency of night awakening in infants, who shared a bed with the caregiver, was not different from the infants who did not share a bed. Bed sharing did not show an association with high SEC of our infants.

Although, the sample size was large and included children from 5 different regions in Thailand, almost 25.0\% of eligible participants were excluded from the analysis, due to missing data for relevant variables, which may have led to a sampling bias. The analyzed group had a higher proportion of unemployed mothers than the missing group. There is a chance that our cohort infants might have poorer SEC compared with the general population. However, any potential exclusion bias in the multivariate analysis was reduced by using the $75^{\text {th }}$ percentile of SEC score as a cut-off point. Another possible limitation was information bias. Information regarding infant's behaviors and night awakening were subjectively measured. It is hard to differentiate awakening and physiologic movement during sleep. Temperament is a known moderator of the relations between parenting styles and children's emotional development ${ }^{32,33}$, but we did not put this in the multivariate analysis; due to the collinearity between temperament and SEC.

Despite the limitations mentioned above, our findings found a bedtime practice potentially promoting the infants' SEC. In this study, recall bias was minimized due to the prospective cohort design. The information was collected over the 7 days prior to each house visit. The caregivers were not aware of the specific study objectives during the interview.

For future study, details of bedtime routines and parental intervention for infant's night awakening should be studied. Feeding to introduce infant's sleep as a bedtime routine may result in a different outcome from feeding until the infant falls asleep. Objective assessment, such as video recording and actigraphy, should be applied to increase internal validity of measures. Long-term follow-up is also recommended.

\section{Conclusion}

This study illustrates the importance of bedtime parenting on the SEC of infants. Non-feeding until the infant fell asleep was associated with high SEC. Our findings also pointed out the difference of parenting, including bedtime practices among cultures.

\section{Acknowledgement}

The authors are grateful to all families who participated in the cohort. We would like to express our gratitude to the following: Ladda Mo-suwan for her helpful suggestions on data analysis and the manuscript; and Wanaporn Anuntaseree, Punnee Vasiknanonte, Chanpen 
Choprapawan, and Taksin Pimpak for their permission to use the dataset of the PCTC. We also thank Nannapat Pruphetkaew for helping with some parts of analyses.

\section{Funding source}

This research did not receive any specific grant from funding agencies in the public, commercial or notfor-profit sectors. (Note: The PCTC, upon which this study was based, was funded by the Faculty of Medicine, Prince of Songkla University; the Thailand Research Fund, the Health Systems Research Institute, the Ministry of Public Health of Thailand and the World Health Organization.)

\section{Conflicts of interest}

The authors have no conflicts of interest to declare.

\section{References}

1. Domitrovich CE, Durlak JA, Staley KC, Weissberg RP. Socialemotional competence: an essential factor for promoting positive adjustment and reducing risk in school children. Child Dev 2017;88:408-16.

2. Augustyn M, Frank DA, Zuckerman BS. Infancy and toddler years. In: Carey WB, Crocker AC, Coleman WL, Elias ER, Feldman $H M$, editors. Developmental-behavioral pediatrics. $4^{\text {th }}$ ed. Philadelphia: Elsevier Saunders; 2009;p.24-38.

3. Olness K. Self-control and self-regulation: normal development to clinical conditions. In: Carey WB, Crocker AC, Coleman WL, Elias ER, Feldman HM, editors. Developmental-behavioral Pediatrics. $4^{\text {th }}$ ed. Philadelphia: Elsevier Saunders; 2009;p.453-60.

4. Owens JA. Sleep medicine. In: Kleigman RM, Stanton BF, St. Geme JW III, Schor NF, Behrman RE, editors. Nelson textbook of pediatrics, vol. 1. $20^{\text {th }}$ ed. Philadelphia: Elsevier Saunders; 2016;p.111-23.

5. Hysing M, Sivertsen B, Garthus-Niegel S, Eberhard-Gran M Pediatric sleep problems and social-emotional problems. A population-based study. Infant Behav Dev 2016;42:111-8.

6. Mindell JA, Leichman ES, DuMond C, Sadeh A. Sleep and social-emotional development in infants and toddlers. J Clin Child Adolesc Psychol 2017;46:236-46.

7. Sivertsen B, Harvey AG, Reichborn-Kjennerud T, Torgersen L,
Ystrom E, Hysing M. Later emotional and behavioral problems associated with sleep problems in toddlers: a longitudinal study. JAMA Pediatr 2015;169:575-82.

8. Magee CA, Gordon R, Caputi P. Distinct developmental trends in sleep duration during early childhood. Pediatrics 2014;133:e1561-7.

9. Field T. Infant sleep problems and interventions: a review. Infant Behav Dev 2017;47:40-53.

10. Covington LB, Armstrong B, Black MM. Perceived toddler sleep problems, co-sleeping, and maternal sleep and mental health. J Dev Behav Pediatr 2018;39:238-45.

11. Brand S, Furlano R, Sidler M, Schulz J, Holsboer-Trachsler E. Associations between infants' crying, sleep and cortisol secretion and mother's sleep and well-being. Neuropsychobiology 2014;69:39-51.

12. Mindell JA, Williamson AA. Benefits of a bedtime routine in young children: sleep, development, and beyond. Sleep Med Rev 2018;40:93-108.

13. Mindell JA, Sadeh A, Wiegand B, How TH, Goh DYT. Crosscultural differences in infant and toddler sleep. Sleep Med 2010;11:274-80.

14. Mileva-Seitz VR, Bakermans-Kranenburg MJ, Battaini C, Luijk MPCM. Parent-child bed-sharing: the good, the bad, and the burden of evidence. Sleep Med Rev 2017;32:4-27.

15. Mindell JA, Sadeh A, Kohyama J, How TH. Parental behaviors and sleep outcomes in infants and toddlers: a cross-cultural comparison. Sleep Med 2010;11:393-9.

16. Anuntaseree W, Mo-suwan L, Vasiknanonte P, Kuasirikul S, Ma-a-lee A, Choprapawan C. Night waking in Thai infants at 3 months of age: association between parental practices and infant sleep. Sleep Med 2008;9:564-71.

17. Douglas PS, Hill PS, Brodribb W. The unsettled baby: how complexity science helps. Arch Dis Child 2011;96:793-7.

18. Tikotzky L. Parenting and sleep in early childhood. Curr Opin Psychol 2017;15:118-24.

19. Gradisar M, Jackson K, Spurrier NJ, Gibson J, Whitham J, Williams AS, et al. Behavioral interventions for infant sleep problems: a randomized controlled trial. Pediatrics 2016;137. doi: 10.1542/peds.2015-1486.

20. Whittingham K, Douglas P. Optimizing parent-infant sleep from birth to 6 months: a new paradigm. Infant Ment Health $J$ 2014;35:614-23. 
21. Ball HL, Douglas PS, Kulasinghe $K$, Whittingham K, Hill P. The Possums infant sleep program: parents' perspectives on a novel parent-infant sleep intervention in Australia. Sleep Health 2018;4:519-26.

22. St James-Roberts I, Roberts M, Hovish K, Owen C. Descriptive figures for differences in parenting and infant night-time distress in the first three months of age. Prim Health Care Res Dev 2016;17:611-21.

23. Mo-Suwan L. Holistic Development of Thai Children Study [monograhp on the Internet]. Bangkok: The Thailand Research Fund; 2004 [cited 2019 May 10]. Available from: https:// elibrary.trf.or.th/project_content.asp?PJID=RDG4310010.Thai

24. R Core Team. R: A language and environment for statistical computing. R Foundation for Statistical Computing V [homepage on the Internet]. Vienna: Scientific Research An Academic Publishing; 2017 [cited 2019 Dec 25]. Available from: https://www.R-project.org/.AU

25. Eisenberg N, Fabes RA, Shepard SA, Guthrie IK, Murphy BC, Reiser M. Parental reactions to children's negative emotions: longitudinal relations to quality of children's social functioning. Child Dev 1999;70:513-34.

26. Hosokawa R, Katsura T. Role of parenting style in children's behavioral problems through the transition from preschool to elementary school according to gender in Japan. Int $J$ Environ Res Public Health 2019;16.
27. Philbrook LE, Teti DM. Bidirectional associations between bedtime parenting and infant sleep: parenting quality, parenting practices, and their interaction. J Fam Psychol 2016;30:43141.

28. Franco M da G, Beja MJ, Candeias A, Santos N. Emotion understanding, social competence and school achievement in children from primary school in Portugal. Front Psychol 2017;8.

29. Hysing M, Harvey A, Torgersen L, Ystrom E, Reichborn-Kjennerud $\mathrm{T}$, Sivertsen B. Trajectories and predictors of nocturnal awakenings and sleep duration in infants. J Dev Behav Pediatr 2014;35:309-16.

30. Santos IS, Barros AJ, Barros FC, Munhoz TN, Da Silva BDP, Matijasevich A. Mother-child bed-sharing trajectories and psychiatric disorders at the age of 6 years. J Affect Disord 2017;208:163-9.

31. Ward TCS. Reasons for mother-infant bed-sharing: a systematic narrative synthesis of the literature and implications for future research. Matern Child Health J 2015;19:675-90.

32. Fields MA, Cole PM, Maggi MC. Toddler emotional states, temperamental traits, and their interaction: associations with mothers' and fathers' parenting. J Res Pers 2017;67:106-19.

33. Klein MR, Lengua LJ, Thompson SF, Moran L, Ruberry EJ, Kiff $\mathrm{C}$, et al. Bidirectional relations between temperament and parenting predicting preschool-age children's adjustment. J Clin Child Adolesc Psychol 2018;47:S113-26. 